\title{
Anticancer activity of isomultiflorenol against human cervical cancer cells due to G2/M cell cycle arrest, autophagy and mitochondrial mediated apoptosis
}

\author{
Juan Li ${ }^{1}$, Yuanyuan Chen ${ }^{2 *}$ \\ ${ }^{1}$ Department of Medical Oncology, ${ }^{2}$ Department of Radiation Oncology, HangZhou Cancer Hospital, HangZhou, \\ ZheJiang310002, China
}

*For correspondence: Email: chenyuan061001@163.com; Tel/Fax: 0086-0571-56006302

Sent for review: 12 January 2020

Revised accepted: 19 June 2020

\begin{abstract}
Purpose: To determine the anticancer effect of a pentacyclic triterpenoid, isomultiflorenol, against human cervical cancer.

Methods: The proliferation of cancer cells was determined using 3-(4,5-dimethylthiazol-2-yl)-2,5diphenyl tetrazolium bromide (MTT) assay. Cell viability was measured with colony forming assay, while flow cytometry was used to study phase distribution in cancer cell mitosis. Electron microscopy was employed for the determination of autophagy induction in the cancer cells, while western blotting was used to assay protein expressions.

Results: Isomultiflorenol significantly $(p<0.05)$ inhibited the proliferation and viability of cervical cancer cells in a concentration-dependent manner. The IC50 of isomultiflorenol was $10 \mu \mathrm{M}$ for HeLa cells, and $90 \mu \mathrm{M}$ for normal EV304 cells. The anti-proliferative effects were exerted as a result of arrest of HeLa cells at G2/M phase. The G2/M phase cells increased from $10.34 \%$ in control to $30.21 \%$ on treatment with $20 \mu \mathrm{M}$ isomultiflorenol. Furthermore, administration of isomultiflorenol led to induction of cancer cell autophagy via mitochondrial apoptotic signaling.

Conclusion: Isomultiflorenol inhibits human cervical cancer cells in vitro by inducing cell cycle arrest and autophagy. Thus, it is a potential lead molecule in the development of cervical cancer chemotherapy.
\end{abstract}

Keywords: Cervical cancer, Terpenoids, Isomultiflorenol, Autophagy, Cell cycle arrest, Apoptosis

\begin{abstract}
This is an Open Access article that uses a fund-ing model which does not charge readers or their institutions for access and distributed under the terms of the Creative Commons Attribution License (http://creativecommons.org/licenses/by/4.0) and the Budapest Open Access Initiative (http://www.budapestopenaccessinitiative.org/read), which permit unrestricted use, distribution, and reproduction in any medium, provided the original work is properly credited.

Tropical Journal of Pharmaceutical Research is indexed by Science Citation Index (SciSearch), Scopus, International Pharmaceutical Abstract, Chemical Abstracts, Embase, Index Copernicus, EBSCO, African Index Medicus, JournalSeek, Journal Citation Reports/Science Edition, Directory of Open Access Journals (DOAJ), African Journal Online, Bioline International, Open-J-Gate and Pharmacy Abstracts
\end{abstract}

\section{INTRODUCTION}

Recent studies on natural compounds have revealed that these compounds exhibit tremendous medicinal and health-promoting properties [1]. Natural compounds exert antiinflammatory, antimicrobial and antioxidant properties [2]. Terpenoids are by far the most predominant class of plant secondary metabolites [3]. A vast number of compounds under the group of terpenoids have been shown to possess strong anticancer properties [4]. They markedly inhibited the proliferation of human cancer cells in in vitro studies [5]. 
Isomultiflorenol (Figure 1) is a pentacyclic triterpenoid [6]. In a previous research, it was demonstrated that isomultiflorenol type of terpenoids were effective in inhibiting the proliferation of number of human cancer cell lines [7]. However, not much is known on the antitumor effects of isomultiflorenol against human cervical cancer. This is the basis of the present study.<smiles></smiles>

Figure 1: Molecular structure of isomultiflorenol

Mortality from human cervical cancer is considerable, and the disease is ranked as the third most prevalent type of cancer in women [8]. In terms of mortality, it is ranked as the fourth in cancer-related deaths among the female population. Human papilloma viral infection is one of the most dominant causes of cervical cancer [8]. The currently-used treatment strategies involve chemotherapy, radiotherapy and HPV vaccinations [9]. However, available information suggests that these anticancer measures are not very efficient. Thus, there is need for alternative treatment methods against human cervical cancer. Against this backdrop, the anticancer effect of isomultiflorenol against cervical cancer, and the underlying mechanism, were investigated in this study.

\section{EXPERIMENTAL}

\section{Cell culture}

The human cervical cancer cell line, HeLa and normal endothelial cell line, ECV304 were brought from the American Type Collection Center (ATCC, USA). Cell culturing was done in DMEM (Thermo Scientific). The medium was supplemented with $10 \%$ FBS and $100 \mathrm{U} / \mathrm{mL}$ penicillin and $100 \mu \mathrm{g} / \mathrm{mL}$ streptomycin. A humidified incubator was used for maintaining the HeLa cells at $37^{\circ} \mathrm{C}$ with $5 \% \mathrm{CO}_{2}$.

\section{Assessment of cell proliferation}

To determine the effect of isomultiflorenol on the proliferation of ECV304 normal cells and HeLa cancer cells, $100 \mu \mathrm{L}$ of their culture containing about $2 \times 10^{4}$ cells were added to each well of 96 -well plate. The wells were incubated with 5 , $10,20,40,80$ and $120 \mu \mathrm{M}$ isomultiflorenol at 37 ${ }^{\circ} \mathrm{C}$ for $48 \mathrm{~h}$. For each treatment, three replicates were used. The wells were then incubated with $10 \mu \mathrm{L}$ MTT [3-(4,5-dimethylthiazol-2-yl)-2,5diphenyltetrazolium bromide] (Thermo Scientific) for $4 \mathrm{~h}$ at $37^{\circ} \mathrm{C}$. Thereafter, DMSO was added to each well to dissolve the formazan crystals formed. The plate was then put into a micro-plate reader to record the absorbance of each well at $570 \mathrm{~nm}\left(\mathrm{OD}_{570}\right)$. The absorbance values were used for assessing the proliferation of the cells.

\section{Determination of cell viability}

The HeLa cancer cells were cultured with or without 5,10 or $20 \mu \mathrm{M}$ isomultiflorenol for 4 days in 6-well plates, with three replicates for every set up. HeLa cell cultures were then harvested and fixed with methanol, after washing thrice with PBS. The cells were then stained with $0.1 \%$ crystal violet, and relative colony numbers were estimated photographically.

\section{Flow cytometry}

In the study of cell cycle phase distribution, the HeLa cancer cells were cultured in 6-well plates with or without 5,10 or $20 \mu \mathrm{M}$ isomultiflorenol for $48 \mathrm{~h}$ at $37^{\circ} \mathrm{C}$. The cells were then harvested, washed with PBS, and then fixed using formaldehyde. Thereafter, they were stained with the fluorescent stain of propidium iodide (PI, Sigma-Aldrich), and a flow cytometer was used to investigate the phase distribution of the PIstained cancer cells.

\section{Transmission electron microscopy (TEM)}

The HeLa cancer cells were inoculated into 6well plates at a density of $2 \times 10^{4}$ cells per well, and were treated with isomultiflorenol at concentrations of 5,10 and $20 \mu \mathrm{M}$ for $24 \mathrm{~h}$. After harvesting and washing with PBS, the cells were fixed with $1 \%$ osmium tetroxide, and dehydrated using graded concentrations of ethanol. The HeLa cells were then embedded in Embed812 resin. Thereafter, ultra-thin sections were obtained using an ultramicrotome, and the slices were post-stained and incubated with lead citrate for electron microscopy. Microphotographs were taken with the aid of transmission electron microscope (GEM-1200ES, Japan).

\section{Western blotting}

After lysing with RIPA buffer, the cell lysates were loaded on $8 \%$ SDS-PAGE gels. The 
separated proteins were transferred to PVDF membranes, and the membranes were blocked with $10 \%$ BSA for $1 \mathrm{~h}$ at $37{ }^{\circ} \mathrm{C}$, and incubated overnight with diluted primary antibodies designed for the specific proteins at $4{ }^{\circ} \mathrm{C}$. Thereafter, the membranes were incubated with secondary antibody. The specific protein bands were detected using high performance chemiluminescence reagent. $\beta$ - Actin was used as a standard.

\section{Statistical analysis}

Statistical tests, viz, $t$-test and one-way ANOVA were performed using GraphPad Prism 5.0 software. When $p$ value obtained was $<0.05$, the difference was considered statistically significant. The data are presented as mean \pm standard deviation (SD).

\section{RESULTS}

Isomultiflorenol selectively decreased the proliferation of HeLa cancer cells

To check whether isomultiflorenol treatment led to decreased proliferation of ECV304 and HeLa cell lines, the cell lines were treated with 5,10 , $20,40,80$ and $120 \mu \mathrm{M}$ isomultiflorenol for $48 \mathrm{~h}$. Results from MTT assay revealed that the proliferation of both cell lines declined significantly $(p<0.05)$ in a concentrationdependent manner (Figure 2). However, the decline in proliferation of HeLa cancer cells was significantly much more prominent than that of ECV304, as was evident from their respective $\mathrm{IC}_{50}$ values. The $\mathrm{IC}_{50}$ value was $10 \mu \mathrm{M}$ for HeLa cells, while it was approximately $90 \mu \mathrm{M}$ for normal EV304 cells. This indicates the selective anti-proliferative effect of isomultiflorenol against the human cervical cancer cells.

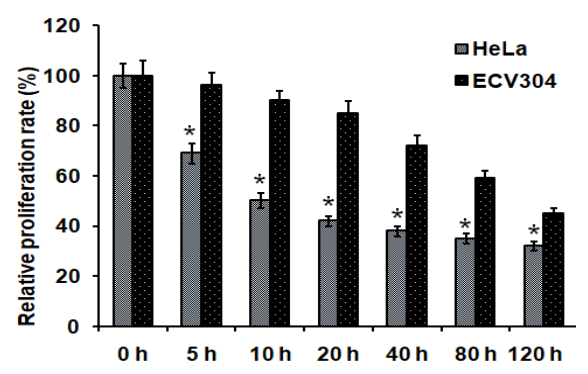

Figure 2: Isomultiflorenol selectively inhibited the proliferation of cervical cancer cells. Percentage proliferations of normal cell line (ECV304) and cancerous cell line (HeLa) treated with 5, 10, 20, 40, 80 or $120 \mu \mathrm{M}$ isomultiflorenol. The experiments were performed in triplicate. Data are expressed as mean \pm $\mathrm{SD}\left({ }^{*} p<0.05\right)$
Isomultiflorenol decreased the viability of HeLa cancer

The HeLa cancer cells were cultured with 5, 10 or $20 \mu \mathrm{M}$ isomultiflorenol for 4 days and then their colony forming potential was assessed. The results indicated that isomultiflorenol, in a concentration dependent manner, decreased the colony-forming potential of HeLa cancer cells (Figure 3). This suggests that isomultiflorenol decreased the viability of cervical cancer cells.

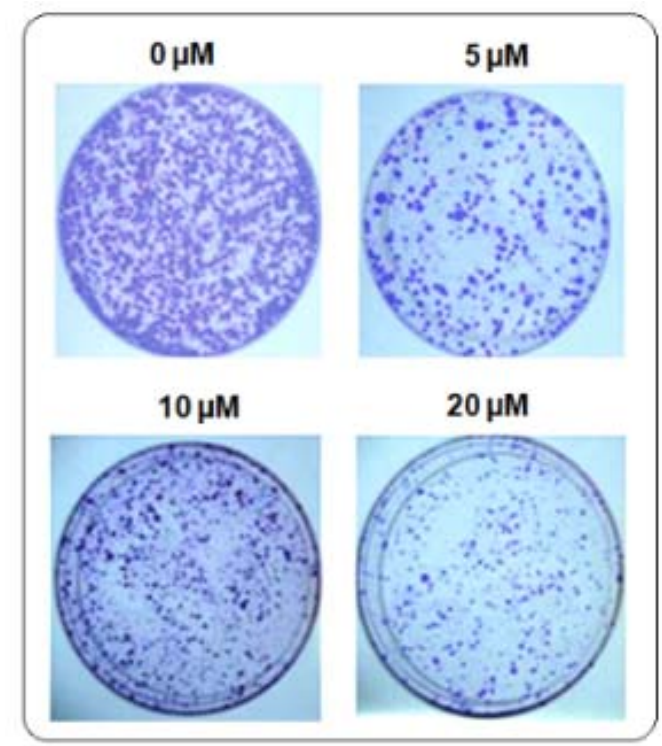

Figure 3: Isomultiflorenol decreased the viability of HeLa cancer cells. Analysis of colony-forming potential of Hela cancer cells treated with 5,10 or $20 \mu \mathrm{M}$ isomultiflorenol

\section{Isomultiflorenol treatment led to cell cycle arrest of HeLa cells at G2/M mitotic phase}

In order to determine if the anti-proliferative role of isomultiflorenol against the HeLa cervical cancer cells was due to induction of cell cycle arrest, the HeLa cells were incubated with 5,10 or $20 \mu \mathrm{M}$ isomultiflorenol, and then cultured for 48 $\mathrm{h}$ at $37^{\circ} \mathrm{C}$. Flow cytometric examination of HeLa cells after $\mathrm{PI}$ staining showed that the relative percentage of HeLa cells in G2 phase increased significantly $(p<0.05)$ with increase in isomultiflorenol concentration (Figure 4A). These results indicate that isomultiflorenol treatment was effective in inducing G2/M cell cycle arrest. This was further confirmed from the Western blotting result for cyclin $\mathrm{BI}$ which protein concentration was seen to decrease with increasing isomultiflorenol dose (Figure 4B). 

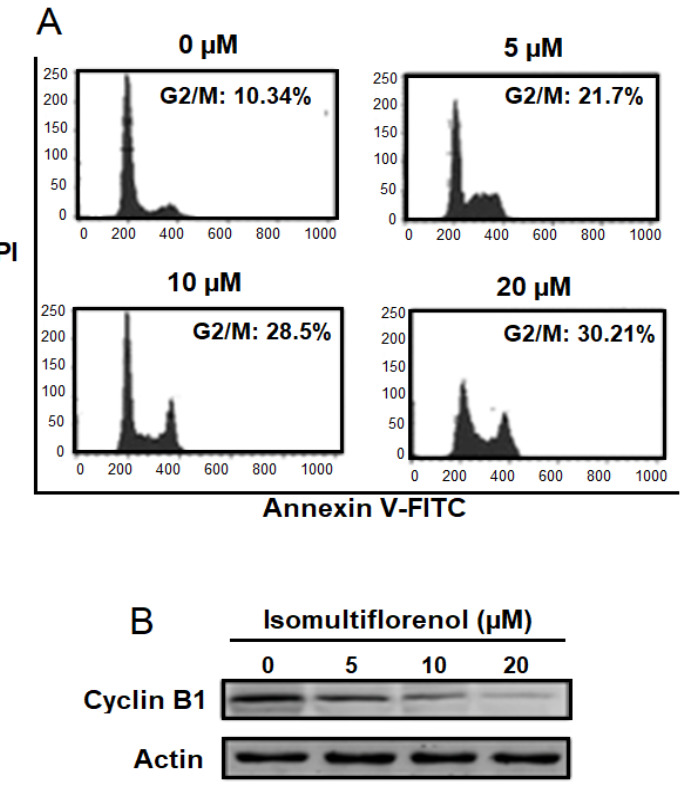

Figure 4: Isomultiflorenol induced $G 2 / M$ phase cell cycle arrest of HeLa cancer cells. (A) Flow cytometric analysis of cell cycle phase distribution of Hela cancer cells treated with 5,10 or $20 \mu \mathrm{M}$ isomultiflorenol. (B) Western blotting of cyclin B1 protein from Hela cancer cells treated with 5,10 or $20 \mu \mathrm{M}$ isomultiflorenol

\section{Autophagy was induced in HeLa cancer cells treated with isomultiflorenol}

Transmission electron microscopic (TEM) study of HeLa cancer cells treated with 5,10 or $20 \mu \mathrm{M}$ isomultiflorenol indicated that the treatment led to generation of autophagic vesicles, as was evident from electron microphotographs (Figure 5). The presence of autophagic vesicles suggested autophagy induction in HeLa cells under isomultiflorenol treatment.

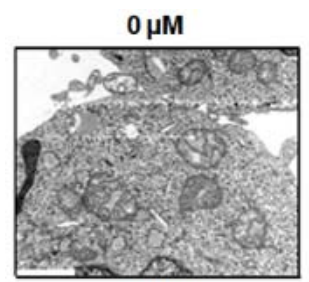

$10 \mu \mathrm{M}$

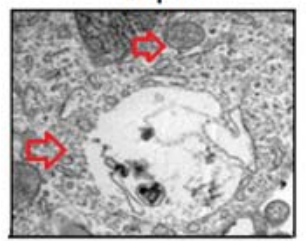

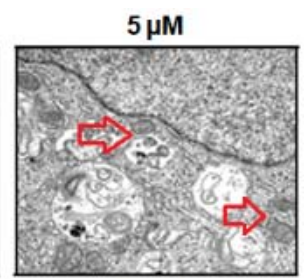

$20 \mu \mathrm{M}$

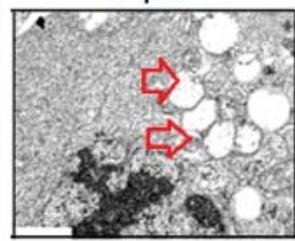

Figure 5: Isomultiflorenol induced autophagy in HeLa cancer cells. TEM study of Hela cancer cells treated with 5,10 or $20 \mu \mathrm{M}$ isomultiflorenol. Arrows depict autophagic vesicles

\section{Isomultiflorenol induced mitochondrial apoptosis in HeLa cells}

The expressions of $\mathrm{p} 53, \mathrm{Bax}$ and $\mathrm{Bcl}-2$ proteins were assayed in HeLa cancer cells treated with 5,10 or $20 \mu \mathrm{M}$ isomultiflorenol using Western blotting, with $\beta$-actin gene as expression control. The results indicated that the concentrations of p53 and Bax proteins increased with increasing concentrations of isomultiflorenol (Figure 6). Moreover, the Bcl-2 protein concentration was seen to decrease in a concentration-dependent manner. These results suggest that isomultiflorenol treatment activated the mitochondrial apoptotic signaling pathway, thereby inducing autophagy in the cervical cancer cells.

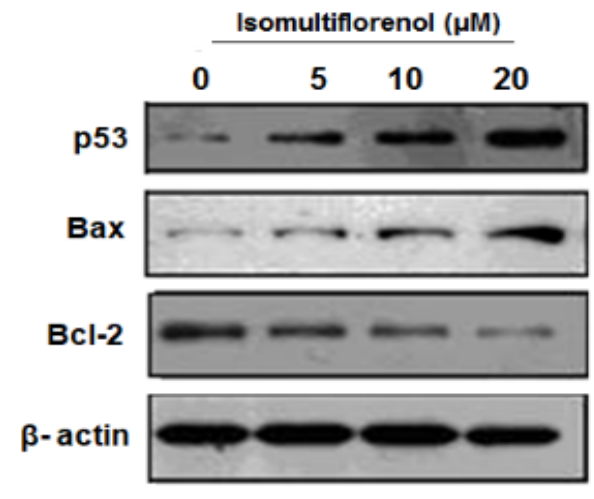

Figure 6: Isomultiflorenol-induced autophagy was modulated through mitochondrial apoptotic cell signaling. Western blotting results for p53, Bax and $\mathrm{Bcl}-2$ proteins from Hela cancer cells treated with 5,10 or $20 \mu \mathrm{M}$ isomultiflorenol

\section{DISCUSSION}

The natural world with its vast diversity of chemical entities provides a vast opportunity for exploration of compounds of interest. Recently, compounds from natural sources have been explored for their beneficial effects on the human health along with their potential for combating different human ailments [10]. These studies have led to the discovery of some very important compounds, including artemisinin [11]. Moreover, natural compounds have been studied for their anticancer effects on different human cancers [12]. A good number of reports have shown that natural compounds are anti-proliferative agents against human cancer cells, and are thus effective in restricting cancer growth [13,14]. Similarly, the anti-cancer effect of isomultiflorenol on human cervical cancer was investigated in the present study. Human cervical cancer is one of the most prevalent cancers in women, worldwide [8]. 
There are reports that anticancer agents currently used against cervical cancer are not very effective for complete cure of this disorder. Hence, there is a need to evolve alternative ways of treating cervical cancer. The present study showed that isomultiflorenol treatment selectively inhibited the proliferation of HeLa cancer cells. Similar observations have been made for other natural compounds against cervical cancer cells in previous studies [15]. The decrease in proliferation of HeLa cells by isomultiflorenol was also evident from its effect on the colony-forming potential of the HeLa cells. The decrease in cell proliferation of HeLa cancer cells was due to the induction of cell cycle arrest of cancer cells at G2/M phase of the cell cycle. Inhibitory effects have also been reported for other terpenoids [16].

Isomultiflorenol was active in the induction of autophagy in HeLa cancer cells. The induction of autophagy was modulated through the mitochondrial apoptosis signaling pathway. The p53 gene is normally maintained at low expression levels. However, when it is overexpressed, it leads to the downregulation of Bcl-2 family proteins $\mathrm{Bcl}-2$ and $\mathrm{Bcl}-\mathrm{x}$, along with enhancement of the pro-apoptotic protein Bax [17]. Together, the increase in p53 and Bax proteins and decrease in Bcl-2 protein act as positive signal for induction of mitochondrial apoptosis pathway. The results of the current study have established that isomultiflorenol induced autophagy in HeLa cancer cells through the mitochondrial apoptosis pathway.

\section{CONCLUSION}

The results of the present study reveal that isomultiflorenol exhibits anticancer effect against human cervical cancer cells by inhibiting their proliferation via autophagy induction driven by mitochondrial apoptotic signal. Thus, isomultiflorenol may be a beneficial lead molecule for the development of efficient chemotherapy for cervical cancer.

\section{DECLARATIONS}

\section{Acknowledgement}

This study was supported by Zhejiang medical and health research project (NO : 2017KY53).

\section{Conflict of interest}

No conflict of interest is associated with this work.

\section{Contribution of authors}

We declare that this work was done by the authors named in this article and all liabilities pertaining to claims relating to the content of this article will be borne by the authors.

\section{Open Access}

This is an Open Access article that uses a funding model which does not charge readers or their institutions for access and distributed under the terms of the Creative Commons Attribution License (http://creativecommons.org/licenses/by/ 4.0) and the Budapest Open Access Initiative (http://www.budapestopenaccessinitiative.org/rea d), which permit unrestricted use, distribution, and reproduction in any medium, provided the original work is properly credited.

\section{REFERENCES}

1. Ji HF, Li XJ, Zhang HY. Natural products and drug discovery. EMBO Rep 2009; 10(3): 194-200.

2. Cicerale $S$, Lucas LJ, Keast RS. Antimicrobial, antioxidant and anti-inflammatory phenolic activities in extra virgin olive oil. CurrOpinBiotech 2012; 23(2): 129135.

3. Graedel TE. Terpenoids in the atmosphere. Rev Geophy 1979; 17(5): 937-47.

4. Cho KS, Lim YR, Lee K, Lee J, Lee JH, Lee IS. Terpenes from forests and human health. ToxicolRes 2017;33(2):97-106.

5. Kuttan G, Pratheeshkumar $P$, Manu KA, Kuttan $R$. Inhibition of tumor progression by naturally occurring terpenoids. Pharm Bio 12011;49(10):995-1007.

6. Hayashi $H$, Huang $P$, Inoue $K$, Hiraoka $N$, Ikeshiro $Y$, Yazaki K, Tanaka S, Kushiro T, Shibuya M, Ebizuka Y. Molecular cloning and characterization of isomultiflorenol synthase, a new triterpene synthase from Luffa cylindrica, involved in biosynthesis of bryonolic acid. Euro J Biochem 2001; 268(23): 63116317.

7. Akihisa $T$, Tokuda $H$, Ichiishi E, Mukainaka T, Toriumi M, Ukiya M, Yasukawa K, Nishino H. Anti-tumor promoting effects of multiflorane-type triterpenoids and cytotoxic activity of karounidiol against human cancer cell lines. Cancer Lett 2001; 173(1): 9-14.

8. Franco EL, Duarte-Franco E, Ferenczy A. Cervical cancer: epidemiology, prevention and the role of human papillomavirus infection. Can Med Assoc J2001; 164(7): 1017-1025.

9. Denny L. Cervical cancer: prevention and treatment. DiscovMed 2012; 14(75): 125-1231.

10. Rao AV, Rao LG. Carotenoids and human health. Pharmacol Res 2007; 55(3): 207-216. 
11. Gelb $\mathrm{MH}$. Drug discovery for malaria: a very challenging and timely endeavor. Curr Opin Chem Biol 2007; 11(4): 440-445.

12. Nobili S, Lippi D, Witort E, Donnini M, Bausi L, Mini E, Capaccioli S. Natural compounds for cancer treatment and prevention. Pharmacol Res 2009; 59(6): 365-378.

13. Boumendjel A, Boccard J, Carrupt PA, Nicolle E, Blanc M, Geze A, Choisnard L, Wouessidjewe D, Matera EL, Dumontet C. Antimitotic and antiproliferative activities of chalcones: forward structure-activity relationship. J Med Chem 2008; 51(7): 2307-2310.

14. Miranda CL, Stevens JF, Helmrich A, Henderson MC, Rodriguez RJ, Yang $Y H$, Deinzer ML, Barnes DW, Buhler DR. Antiproliferative and cytotoxic effects of prenylated flavonoids from hops (Humulus lupulus) in human cancer cell lines. Food Chem Toxicol 1999; 37(4): 271-285.

15. Shi X, Xu M, Luo K, Huang W, Yu H, Zhou T. Anticancer activity of bergenin against cervical cancer cells involves apoptosis, cell cycle arrest, inhibition of cell migration and the STAT3 signalling pathway. Exp Therap Med 2019; 17(5): 3525-3529.

16. Xian $M$, Ito $K$, Nakazato $T$, Shimizu $T$, Chen $C K$, Yamato K, Murakami A, Ohigashi $H$, Ikeda $Y$, Kizaki M. Zerumbone, a bioactive sesquiterpene, induces G2/M cell cycle arrest and apoptosis in leukemia cells via a Fas-and mitochondria-mediated pathway. Cancer Sci 2007; 98(1): 118-126.

17. Shu KX, Li B, Wu LX. The p53 network: $p 53$ and its downstream genes. Colloids and Surfaces $B$ : Biointerfaces 2007; 15; 55(1): 10-18. 